\title{
Probing hydrazine with a near-infrared fluorescent
}

\section{chemodosimeter}

\author{
Jianhua Ma ${ }^{1}$, Jiangli Fan ${ }^{1}$, Haidong Li ${ }^{1}$, Qichao Yao ${ }^{1}$, Jing Xia ${ }^{2}$, Jingyun Wang ${ }^{2}$, \\ Xiaojun Peng ${ }^{1, *}$
}

\begin{abstract}
Hydrazine is highly toxic to humans and animals when inhaled or in contact with the skin. It is also a very important chemical used as propellant, metal corrosion inhibitor, pharmaceutical and intermediate. The simple detection of hydrazine in solution and biosystems becomes very important as a consequence of the foregoing applications. Herein, we report a two-photon fluorescent probing method using a NIR fluorescent chemodosimeter, displaying turn-on fluorescence and color change after cleaving an $O$-acetyl moiety by hydrazine, which exhibits good selectivity and sensitively in solution and living cells.
\end{abstract}

Keywords: two-photon; near-infrared; fluorescent chemodosimeter; hydrazine; living cells

\section{Introduction}

Hydrazine $\left(\mathrm{N}_{2} \mathrm{H}_{4}\right)$, as an important propellant, is often applied in rocket-propulsion systems for its flammable and detonable characteristics [1]. It is an important metal corrosion inhibitor because of its strong reducing properties and scavenges oxygen in water boilers for feed and 1 
heating systems [2]. It is also used as a common precursor in the synthesis of various polymers, direct hydrazine fuel cells in power generation sector and pharmaceutical intermediates in the materials field [3-6]. However, hydrazine and its aqueous solutions are highly toxic to humans and animals when inhaled or in contact with skin. It has been reported that hydrazine is carcinogenic and mutagenic and may cause serious damage to the liver, lungs, kidneys and the human central nervous system $[7,8]$. Therefore, it is of great interest and importance to develop reliable method to detect hydrazine with satisfactory sensitivity and selectivity.

In recent years, a few analytical technologies have been developed to determination of hydrazine in the chemical system, such as chromatography [9, 10], chemiluminescence [11], spectrophotometry [12], electrochemistry [13], titrimetry [14], and surface-enhanced Raman spectroscopy [15]. However, most of these methods are effective for extracellular hydrazine and require sample preparation steps. Only a few of these methods can be used to detect intracellular hydrazine. Fluorescent probes have become powerful tools for monitoring the extracellular and intracellular levels of biologically relevant species and to understand their functions because of the rapid, nondestructive, selective, and sensitive advantages of emission signals [16-22]. Colorimetric fluorescent probes display excellent property for small molecule detection [23-26]. A ratiometric and colorimetric NIR fluorescent sensor in our previous work, which incorporated an acetyl moiety into heptamethine cyanine dye derivative, could image $\mathrm{N}_{2} \mathrm{H}_{4}$ in MCF-7 cells and nude mouse with low biological toxicity [27]. The introduced acetyl moiety in the probe could be cleaved by hydrazine with good selectivity and suitable reaction time.

Compared with the traditional one-photon microscopy technique (OPM), TPM (two-photon microscopy) acquires the excited state of a fluorophore by utilizing two-photons of lower energy. The excellent property of TPM is superior to OPM because of lower phototoxicity, better three dimensional spatial localization, deeper penetration depth and lower self-absorption. To date, there are few two-photon (TP) probes have been designed for $\mathrm{N}_{2} \mathrm{H}_{4}$ imaging. For example, Meng's group has synthesized a novel quinoline-based ratiometric two-photon fluorescent probe for the specific detection of $\mathrm{N}_{2} \mathrm{H}_{4}$, and the TPM imaging of this probe in CHO cells [28]. However, almost all reported TP probes have short maximum emission wavelengths less than $600 \mathrm{~nm}$ which limit their biological applications because of low spectral interference caused by nonspecific 
absorption and fluorescence of the complex matrix. Therefore, it is of great value to develop a new TP fluorescent probe with near-infrared emission for $\mathrm{N}_{2} \mathrm{H}_{4}$ determination which will definitely have more practical applications.

Herein, we report a new two-photon colorimetric fluorescent probe BI-E to detect the $\mathrm{N}_{2} \mathrm{H}_{4}$ with high selectivity and sensitivity in vitro and in vivo. The donor- $\pi$-acceptor structure chromophore dicyanomethylene- $4 H$-pyran has been exploited as a colorimetric fluorophore in the detection of glutathione [29], hydrogen peroxide [30, 31] and fluoride [32]. We introduce an $O$-acetyl moiety into dicyanomethylene- $4 H$-pyran skeleton to obtain the fluorescent probe BI-E which be cleaved by reaction with $\mathrm{N}_{2} \mathrm{H}_{4}$ and release a DCPO$^{-}$fluorophore with a maximum emission at $680 \mathrm{~nm}$ (Scheme 1).

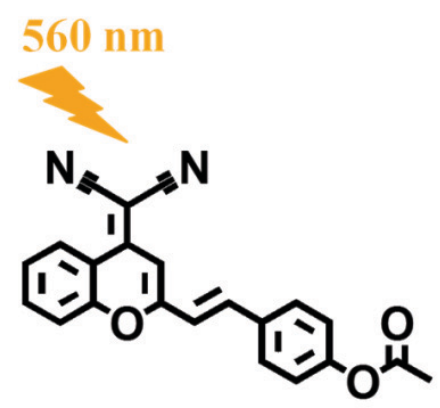

\section{BI-E} Fluorescence off

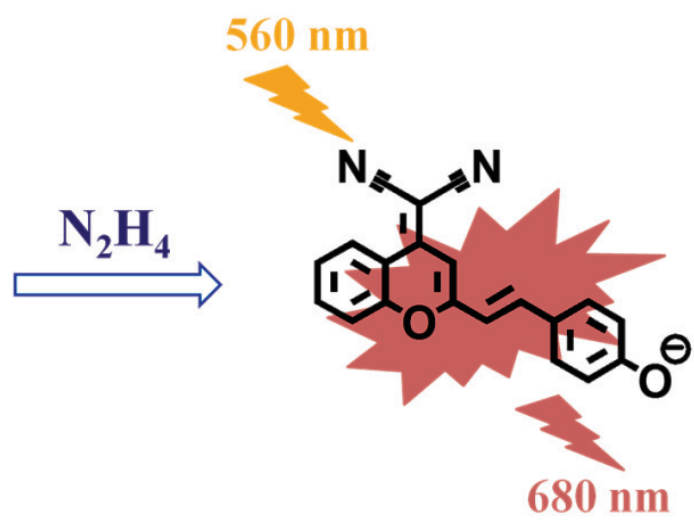

DCPO- $^{-}$ Fluorescence on

Scheme 1. The structure and reaction mechanism of the probe BI-E.

\section{Materials and Methods}

\subsection{General}

All solvents and reagents used were reagent grade and were used without further purification unless specified. The stock solution of BI-E was dissolved in DMSO at a concentration of $1 \mathrm{mM}$ and stored in a refrigerator for use. ${ }^{1} \mathrm{H}$ NMR and ${ }^{13} \mathrm{C}$ NMR spectra were recorded on a VARIAN INOVA-400 (or a Bruker Avance II $400 \mathrm{MHz}$ or $500 \mathrm{MHz}$ ) spectrometer. Chemical shifts $(\delta)$ in ppm (in $\mathrm{CDCl}_{3}$ or Acetone-d ${ }^{6}$, with TMS as the internal standard). VARIAN CARY Eclipse 
fluorescence spectrophotometer (Serial No. FL0812-M018) was used for fluorescence spectroscopy. A Perkin Elmer Lambda 35 UV/VIS spectrophotometer (Perkin Elmer) was used for measuring absorption spectroscopy. HRMS spectrometric data were reported on HP1100LC/MSD MS and LC/Q-TOF-MS instruments. A Model PHS-3C meter was used for all $\mathrm{pH}$ measurements. The $\mathrm{HCl}$ or $\mathrm{NaOH}$ stock solution was prepared at a concentration of $1 \mathrm{M}$ for slight pH changes. Silica gel (100 - 200 mesh) and aluminum oxide (neutral. 100 - 200 mesh)

bought from Qingdao Ocean Chemicals were used for flash column chromatography. Doubly purified water used in all experiments was from Milli-Q systems. All measurements were recorded at room temperature.<smiles>CC(=O)c1ccccc1O</smiles><smiles>CC(=O)CC(=O)c1ccccc1O</smiles>
1

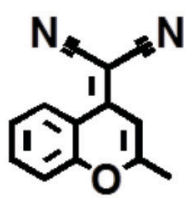

3
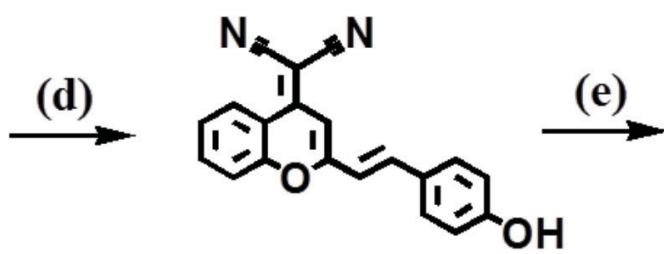

DCPO

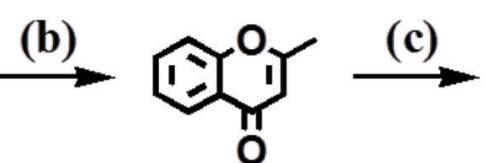

2

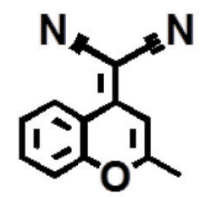

3

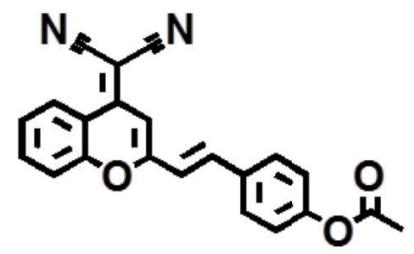

BI-E

Scheme 2. The synthetic route of probe BI-E. Reagent and conditions: (a) $\mathrm{Na}, \mathrm{CH}_{3} \mathrm{COOC}_{2} \mathrm{H}_{5}, 4 \mathrm{~h}, 49.6 \%$; (b) AcOH, $\mathrm{H}_{2} \mathrm{SO}_{4}, 30 \mathrm{~min}, 78.0 \%$; (c) malononitrile, $\mathrm{AcOH}, \mathrm{H}_{2} \mathrm{SO}_{4}, 14 \mathrm{~h}, 35.5 \%$; (d) 4-hydroxybenzaldehyde, toluene, piperidine, $\mathrm{AcOH}, 12 \mathrm{~h}, 50.3 \%$ (e) acetyl chloride, $\mathrm{Et}_{3} \mathrm{~N}, \mathrm{CH}_{2} \mathrm{Cl}_{2}$, r.t., $90.0 \%$.

\subsection{Synthesis of compounds}

\subsubsection{Synthesis of compound DCPO}

2-(2-(4-Hydroxystyryl)-4H-chromen-4-ylidene) malononitrile (DCPO) was synthesized according to the procedure published in literature [33]. 2-(2-Methyl-4H-chromen-4-ylidene) malononitrile $(208 \mathrm{mg}, 1.00 \mathrm{mmol})$ and 4-hydroxybenzaldehyde $(387.5 \mathrm{mg}, 1.10 \mathrm{mmol})$ were dissolved in anhydrous toluene $(25 \mathrm{~mL})$. After adding piperidine $(1.21 \mathrm{ml})$ and acetic acid $(0.5 \mathrm{ml})$, the solution was heat to reflux for $12 \mathrm{~h}$. The mixture was cooled to room temperature and the solvent removed under vacuum. The residue was purified by a flash column chromatography and 
the red solid product was obtained (251.5mg, 50.3\%). Mp: $257-259{ }^{\circ} \mathrm{C} .{ }^{1} \mathrm{H}$ NMR $(400 \mathrm{MHz}$, Acetone) $\delta 8.81(\mathrm{dd}, \mathrm{J}=8.4,1.3 \mathrm{~Hz}, 1 \mathrm{H}), 7.87(\mathrm{ddd}, \mathrm{J}=8.5,7.3,1.4 \mathrm{~Hz}, 1 \mathrm{H}), 7.71(\mathrm{dd}, \mathrm{J}=8.6$, $7.6 \mathrm{~Hz}, 2 \mathrm{H}), 7.63(\mathrm{~d}, \mathrm{~J}=8.6 \mathrm{~Hz}, 2 \mathrm{H}), 7.59-7.52(\mathrm{~m}, 1 \mathrm{H}), 7.12(\mathrm{~d}, \mathrm{~J}=15.9 \mathrm{~Hz}, 1 \mathrm{H}), 6.93(\mathrm{~d}, \mathrm{~J}=$ $8.6 \mathrm{~Hz}, 2 \mathrm{H}), 6.84(\mathrm{~s}, 1 \mathrm{H}) .{ }^{13} \mathrm{C}$ NMR (101 MHz, Acetone) $\delta 160.12,158.78,152.74,152.43$, $139.20,134.89,130.21,126.78,125.79,125.08,118.85,117.55,116.98,116.06,115.87,115.61$, 105.65, 60.70. IR (KBr, cm $\left.{ }^{-1}\right): 3396,2939,2210,1693,1631,1598,1556,1513,1496,1481,1442$, $1405,1265,1168,973,840,823,745$. HRMS (ESI) calcd for $\mathrm{C}_{20} \mathrm{H}_{12} \mathrm{~N}_{2} \mathrm{O}_{2}[\mathrm{M}-\mathrm{H}]^{-} 311.0826$, found 311.0826.

\subsubsection{Synthesis of probe BI-E}

To a solution of 2-(2-(4-Hydroxystyryl)-4H-chromen-4-ylidene) malononitrile (DCPO) (300 $\mathrm{mg}, 0.96 \mathrm{mmol})$ and triethylamine $(302 \mathrm{mg}, 3.0 \mathrm{mmol})$ in anhydrous dichloromethane $(20 \mathrm{~mL})$ at $0{ }^{\circ} \mathrm{C}$, acetyl chloride $(73 \mathrm{mg}, 0.93 \mathrm{mmol})$ was added under a nitrogen atmosphere. Then the mixture was stirred for another $2 \mathrm{~h}$ until the reaction was complete. The concentrated mixture was dissolved in dichloromethane and then washed with water, brine and dried with $\mathrm{MgSO}_{4}$. Then the residue was purified by a flash column chromatography and the yellow solid product was obtained (305.9 mg, 90.0\%). Mp: $235-236^{\circ} \mathrm{C} .{ }^{1} \mathrm{H}$ NMR $\left(400 \mathrm{MHz}, \mathrm{CDCl}_{3}\right) \delta 8.92(\mathrm{~d}, \mathrm{~J}=8.3 \mathrm{~Hz}, 1 \mathrm{H})$, $7.74(\mathrm{~d}, \mathrm{~J}=8.1 \mathrm{~Hz}, 1 \mathrm{H}), 7.68-7.52(\mathrm{~m}, 4 \mathrm{H}), 7.47(\mathrm{~d}, \mathrm{~J}=7.5 \mathrm{~Hz}, 1 \mathrm{H}), 7.19(\mathrm{~d}, \mathrm{~J}=8.4 \mathrm{~Hz}, 2 \mathrm{H})$, $6.88(\mathrm{~s}, 1 \mathrm{H}), 6.78(\mathrm{~d}, \mathrm{~J}=16.1 \mathrm{~Hz}, 1 \mathrm{H}), 2.33(\mathrm{~s}, 3 \mathrm{H}) .{ }^{13} \mathrm{C} \mathrm{NMR}\left(101 \mathrm{MHz}, \mathrm{CDCl}_{3}\right) \delta 169.11$, $157.19,152.79,152.32,152.27,137.71,134.71,132.35,129.05,126.04,125.87,122.45,118.92$, 118.63, 117.84, 116.68, 115.60, 107.03, 63.18, 21.16. IR (KBr, $\left.\mathrm{cm}^{-1}\right): 3436,2925,2853,2208$, $1749,1724,1631,1598,1560,1502,1481,1456,1405,1369,1263,1224,1201,1166,1010,983$, 844, 768. HRMS (ESI) calcd for $\mathrm{C}_{22} \mathrm{H}_{14} \mathrm{~N}_{2} \mathrm{O}_{3}[\mathrm{M}+\mathrm{Na}]^{+}$377.0897, found 377.0902.

\subsection{Cell culture and confocal fluorescence imaging}

MCF-7 cells were cultured in DMEM medium supplemented with $10 \%$ fetal bovine serum at 37 ${ }^{\circ} \mathrm{C}$ in an atmosphere containing $5 \% \mathrm{CO}_{2}$. For live cell imaging, cells grown in a glass bottom dish were incubated with compound for 30 min and wash with DMEM three times. Then cells were imaged using a confocal fluorescence microscope (OLYMPUS, FV1000) for one-photon 
microscopy imaging (OPM) and two-photon microscopy (TPM) imaging. A high-performance mode-locked titanium-sapphire laser source (MaiTai, Spectra-Physics USA) was used for TPM imaging. The images of DCPO were obtained with the emission in the range of $650-750 \mathrm{~nm}$ for OPM and $575 \mathrm{~nm}-630 \mathrm{~nm}$ for TPM.

\subsection{Cytotoxic assay}

MCF-7 cells were used for estimating the cytotoxicity of BI-E. Briefly, Cells were seeded in a 96-well plate. On the following day, cells were incubated with $5 \mu \mathrm{M}$ BI-E for $12 \mathrm{~h}$ and $24 \mathrm{~h}$ at 37 ${ }^{\circ} \mathrm{C}$. Subsequently, $100 \mu \mathrm{L}$ of 3-(4,5-dimethylthiazol-2-yl)-2,5-diphenyltetrazolium bromide (MTT, Sigma Chemical Co. USA) was added into each well, followed by further incubation for $24 \mathrm{~h}$ at $37^{\circ} \mathrm{C}$. The DMEM was remove and DMSO (200 $\mu \mathrm{L} /$ well) added. Optical density (OD) was measured by a microplate reader (Spectra Max M5, Molecular Devices) at $570 \mathrm{~nm}$ with subtraction of the absorbance of the cell-free blank volume at $630 \mathrm{~nm}$. The relative cell viability $(100 \%)$ was calculated using the following formula: cell viability $(\%)=\left(\mathrm{OD}_{\mathrm{dye}}-\mathrm{OD}_{\mathrm{K}}\right.$ dye $) /(\mathrm{OD}$ control $\left.-\mathrm{OD}_{\mathrm{K} \text { control }}\right) \times 100$, where dye stands for the BI-E sample.

\section{Results and discussion}

\subsection{Systhesis of probe BI-E}

BI-E was synthesized according to the route shown in Scheme 2 as a yellow solid in several steps and has been characterized by IR, ${ }^{1} \mathrm{H}$ NMR, ${ }^{13} \mathrm{C}$ NMR and HRMS. It is slightly soluble in water, but can dissolve in normal organic solvent such as dichloromethane, chloroform and DMSO.

\subsection{UV-vis and fluorescence responses}

The absorption and fluorescence properties of BI-E were determined in PBS $(\mathrm{pH}=7.4)$ solution containing 50\% of ethanol (Fig. 1 and Fig. S1). BI-E has two main absorption peaks at around 414 $\mathrm{nm}$ and $434 \mathrm{~nm}$. After treatment of BI-E with $\mathrm{N}_{2} \mathrm{H}_{4}$ for 1min, two new absorption peaks appeared at $388 \mathrm{~nm}$ and $551 \mathrm{~nm}$ with a decrease of peak at $414 \mathrm{~nm}$ and disappearing at $434 \mathrm{~nm}$. The maximum absorption peak shifted from $434 \mathrm{~nm}$ to $551 \mathrm{~nm}$. Addition of BI-E with increasing 
concentrations of $\mathrm{N}_{2} \mathrm{H}_{4}$, the absorption titration curves decreased gradually at $414 \mathrm{~nm}$ and

152 increased at $551 \mathrm{~nm}$ indicating the capacity of BI-E for colorimetric detection of $\mathrm{N}_{2} \mathrm{H}_{4}$. There was a good linearity between the absorption intensity ratio $\left(\mathrm{A}_{551} / \mathrm{A}_{414}\right)$ and concentration of $\mathrm{N}_{2} \mathrm{H}_{4}$ ranging from $0-40 \mu \mathrm{M}$. The photo-stability of both BI-E and DCPO is much better than Cy7-Cl (structure in Fig. S2b) after exposure to high density light (500W, tungsten lamp) for $100 \mathrm{~min}$, which is a critical factor for bioimaging in vivo (Fig. S2a).

Probe BI-E showed almost no fluorescence emission upon excitation at $560 \mathrm{~nm}$. Addition of $\mathrm{N}_{2} \mathrm{H}_{4}$ resulted in an obvious increase at $680 \mathrm{~nm}$. With increasing concentrations of $\mathrm{N}_{2} \mathrm{H}_{4}$, the fluorescence titration spectrum showed a gradual enhancement. $\mathrm{N}_{2} \mathrm{H}_{4}$ elicited a more than 110-fold fluorescence increase. Mass spectrometry data along with absorption and emission spectra showed that the $\mathrm{N}_{2} \mathrm{H}_{4}$-medicated acetyl deprotection of BI-E generated DCPO as the fluorescence product (Fig. S3 and Fig. S4). The fluorescence intensity of BI-E increasing obviously at $680 \mathrm{~nm}$ after treatment of $\mathrm{N}_{2} \mathrm{H}_{4}$ with a Stokes shift $120 \mathrm{~nm}$ indicated that it was suitable for the detection of $\mathrm{N}_{2} \mathrm{H}_{4}$ in vivo and in vitro.
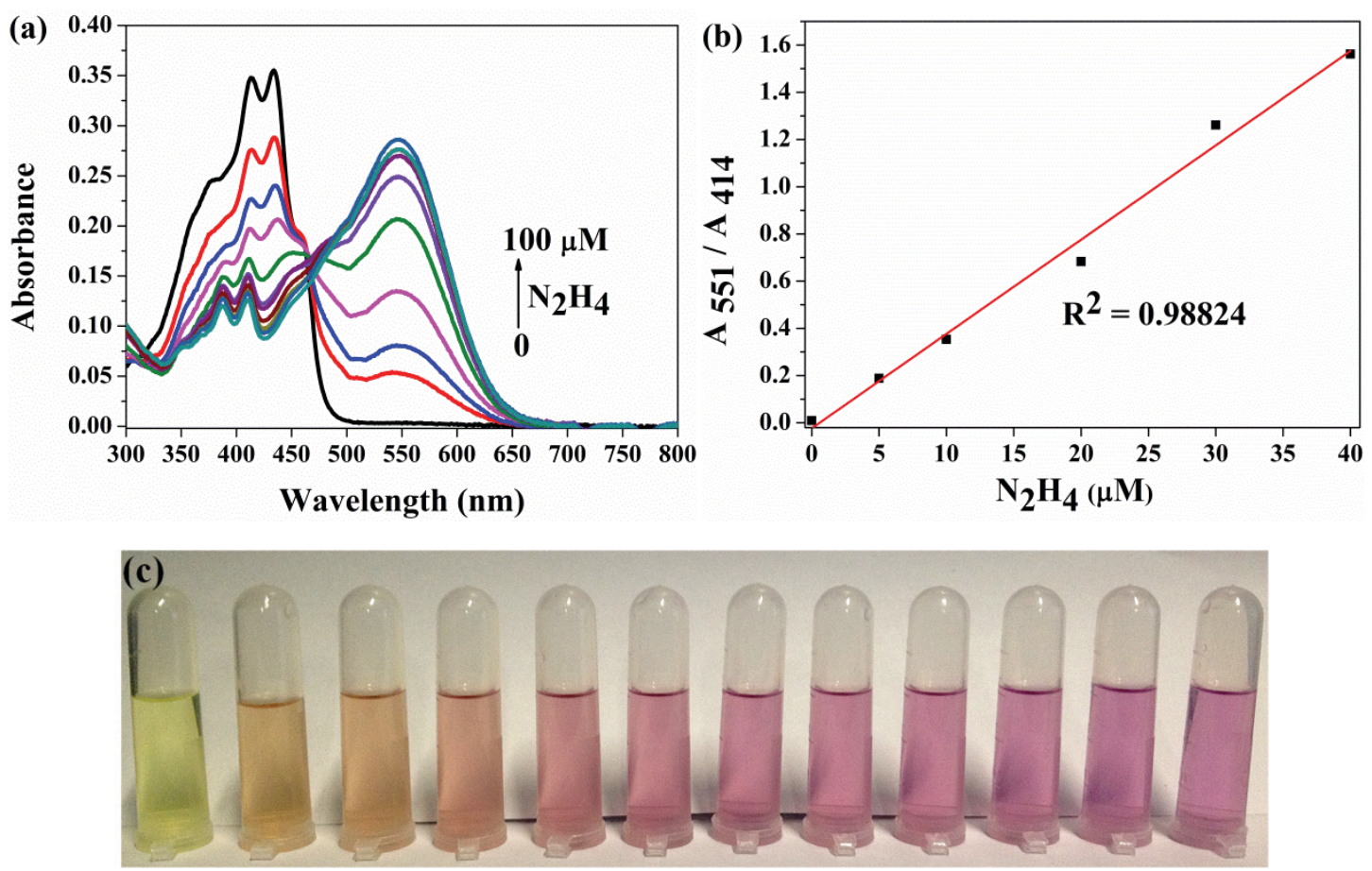

Fig. 1. (a) Absorption spectra of probe BI-E $(10 \mu \mathrm{M})$ in the presence of different concentration of $\mathrm{N}_{2} \mathrm{H}_{4}(0,5,10$, 

S5).

(a)

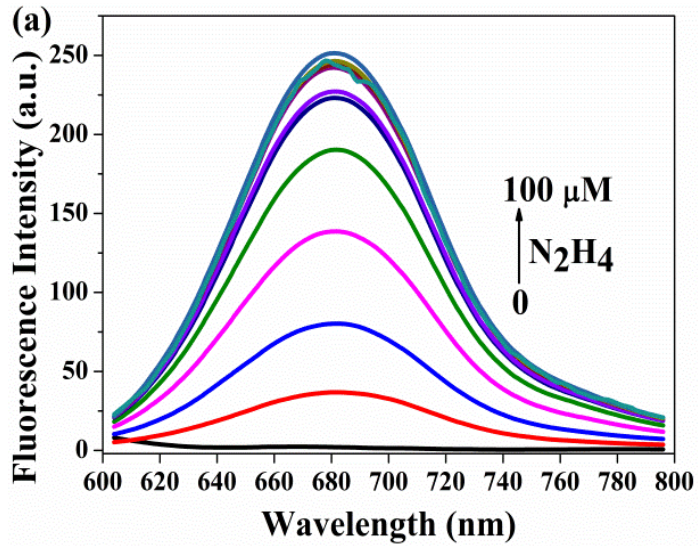

182

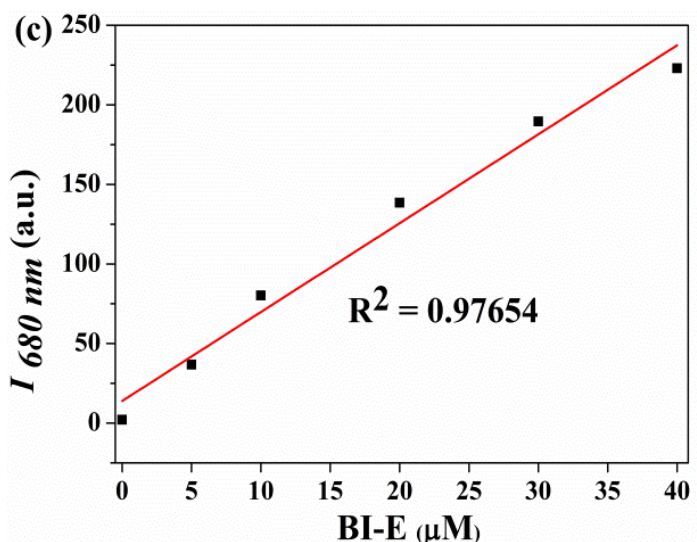

changes of BI-E $(10 \mu \mathrm{M})$ to different concentration of $\mathrm{N}_{2} \mathrm{H}_{4}(0,5,10,20,30,40,50,60,70,80,90$ and $100 \mu \mathrm{M})$.

To further identify the performance of BI-E, the fluorescence of the probe was measured by fluorescence titration experiment. In a certain range, the fluorescence intensity increased gradually following the increased concentration of $\mathrm{N}_{2} \mathrm{H}_{4}$ (Fig. 2a and Fig. 2b). There was a good linearity between the fluorescence intensity at $680 \mathrm{~nm}$ and the concentration of $\mathrm{N}_{2} \mathrm{H}_{4}$ ranging from $0-40$ $\mu \mathrm{M}$ (Fig. 2c). The detection limit of $\mathrm{N}_{2} \mathrm{H}_{4}$ was calculated from the equation $\mathrm{DL}=3 \sigma / \mathrm{S}$, where $\sigma$ is the standard deviation of a blank measurement and $\mathrm{S}$ is the slope between intensity versus sample concentration. The detection limit of BI-E was calculated to be $5.7 \times 10^{-8} \mathrm{M}$. The time-dependent fluorescent change measurements showed the response time of BI-E toward $\mathrm{N}_{2} \mathrm{H}_{4}$ was 1 min (Fig. 2d). The $\mathrm{pH}$ experiments indicated that BI-E could detect $\mathrm{N}_{2} \mathrm{H}_{4}$ in physiological $\mathrm{pH}$ range (Fig.
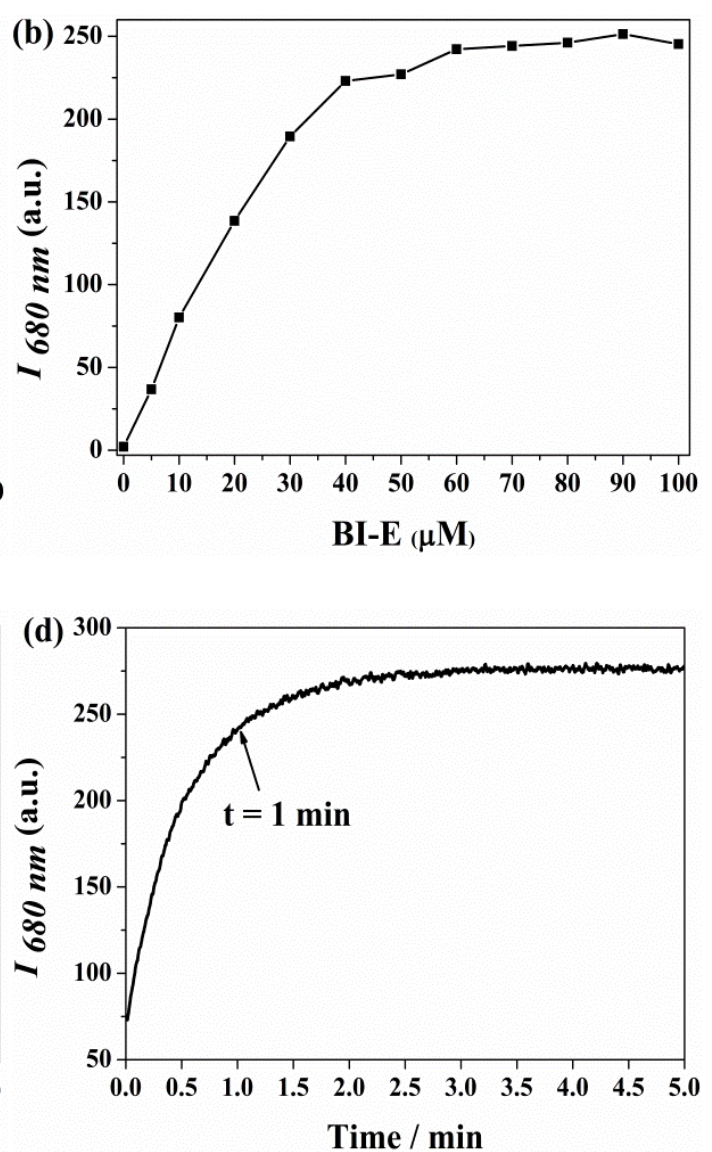

Fig. 2. (a) and (b) Emission spectra of probe BI-E $(10 \mu \mathrm{M})$ in the presence of different concentration of $\mathrm{N}_{2} \mathrm{H}_{4}(0$, 
$5,10,20,30,40,50,60,70,80,90$ and $100 \mu \mathrm{M}, 1 \mathrm{~min}$ ) ; (c) a linear correlation between emission intensity and concentration of $\mathrm{N}_{2} \mathrm{H}_{4}$ at $680 \mathrm{~nm}$; (d) Time-dependent fluorescence changes of BI-E upon addition of $\mathrm{N}_{2} \mathrm{H}_{4}(100$ $\mu \mathrm{M})$ at $680 \mathrm{~nm}$. Emission spectra obtained in solution (Ethanol/PBS $=5 / 5, \mathrm{pH}=7.4$ ) upon excitation at $560 \mathrm{~nm}$.

\section{3. $\mathrm{N}_{2} \mathrm{H}_{4}$ selective and competitive experiment}

The selectivity of BI-E was examined towards $\mathrm{N}_{2} \mathrm{H}_{4}$ and other amino acids and various cations. As a result, only $\mathrm{N}_{2} \mathrm{H}_{4}$ induced an obvious fluorescence intensity increase at $680 \mathrm{~nm}$. There was little fluorescence intensity increase when BI-E treated with other chemicals (Fig. 3a and Fig. S6). Besides, BI-E had a good selectivity for $\mathrm{N}_{2} \mathrm{H}_{4}$ when mixing with others in competitive experiment (Fig. 3b and Fig. S7). These results indicated that BI-E has reasonable activity and selectivity to identify $\mathrm{N}_{2} \mathrm{H}_{4}$ in a complex environment.
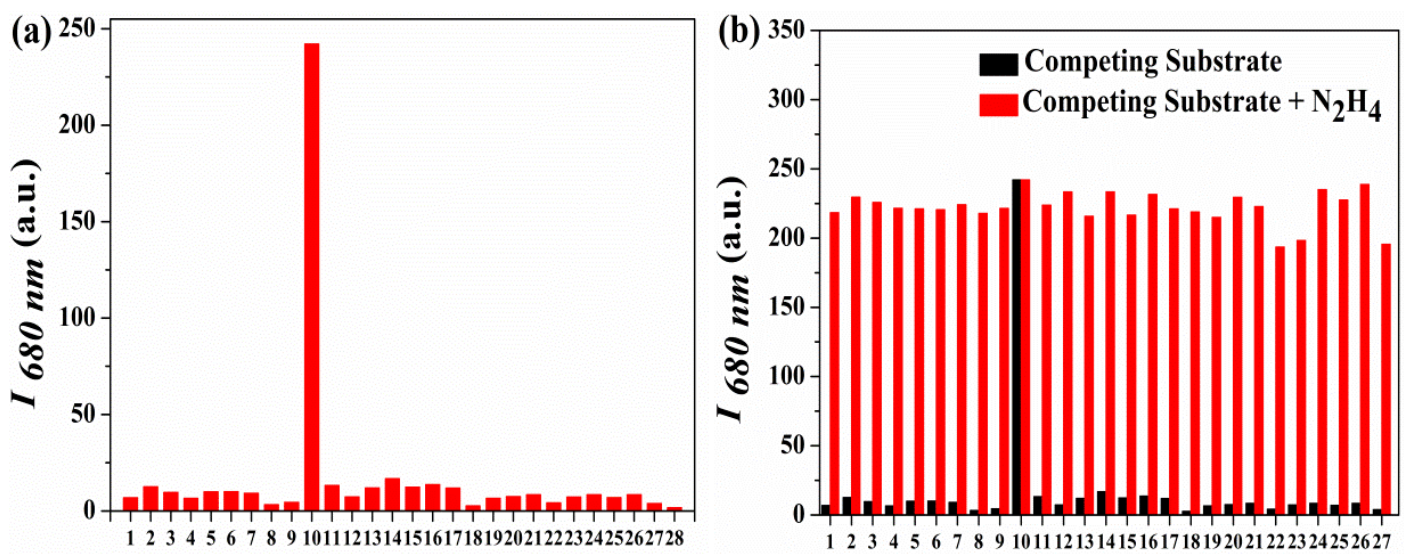

Fig. 3. Selective (a) and competitive (b) experiment in solution (Ethanol/PBS $=5 / 5, \mathrm{pH}=7.4$ ) with the emission intensity at $680 \mathrm{~nm}$, .(a) Fluorescence response of BI-E $(10 \mu \mathrm{M})$ to various analytes $(100 \mu \mathrm{M})$, Each spectrum was recorded at $1 \mathrm{~min}$ after addition of the analytes (from 1 to 28 represent Ala, Arg, Asn, Asp, Gln, Glu, Gly, GSH, Hcy, Cys, His, Leu, Phe, Pro, Trp, Thr, Val, NaHS, $\mathrm{K}^{+}, \mathrm{Na}^{+}, \mathrm{Fe}^{2+}, \mathrm{Fe}^{3+}, \mathrm{Ba}^{2+}, \mathrm{Mg}^{2+}, \mathrm{Cu}^{2+}, \mathrm{Ca}^{2+}, \mathrm{Zn}^{2+}$ and BI-E); (b) Fluorescence intensity of BI-E $(10 \mu \mathrm{M})$ in the presence of various analytes $(100 \mu \mathrm{M})$ (from 1 to 27 represent Ala, Arg, Asn, Asp, Gln, Glu, Gly, GSH, Hcy, Cys, His, Leu, Phe, Pro, Trp, Thr, Val, NaHS, $\mathrm{K}^{+}, \mathrm{Na}^{+}, \mathrm{Fe}^{2+}, \mathrm{Fe}^{3+}$, $\left.\mathrm{Ba}^{2+}, \mathrm{Mg}^{2+}, \mathrm{Cu}^{2+}, \mathrm{Ca}^{2+}, \mathrm{Zn}^{2+}\right)$. Black bars represent the addition of 10 equiv of the appropriate analytes to a $10 \mu \mathrm{M}$ 
solution of BI-E. Red bars represent the addition of BI-E $(10 \mu \mathrm{M})$ to the mixture solution of $100 \mu \mathrm{M}$ the appropriate analytes and $100 \mu \mathrm{M} \mathrm{N}_{2} \mathrm{H}_{4}$.

\subsection{Measurement of Two-Photon Cross-Section.}

The two-photon cross-section of BI-E and DCPO $(100 \mu \mathrm{M})$ were measured in $1 \mathrm{~mL}$ PBS buffer $(\mathrm{pH}=7.4)$ containing $50 \%$ of ethanol as described in literature [34]. The quantum yield of BI-E and DCPO were measured by Absolute PL Quantum Yield Spectrometer (HAMAMATSU C11347). The quantum yield is 0.002 for BI-E and 0.011 for DCPO in solution (Ethanol/PBS = $5 / 5, \mathrm{pH}=7.4)$. The cross-sections of BI-E and DCPO were calculated by using the following formula: $\delta=\delta_{\mathrm{r}} \times\left(\mathrm{F}_{\mathrm{s}} \times \phi_{\mathrm{r}} \times \mathrm{n}_{\mathrm{r}}\right) /\left(\mathrm{F}_{\mathrm{r}} \times \phi_{\mathrm{s}} \times \mathrm{n}_{\mathrm{s}}\right)$, where $\delta, \mathrm{F}, \phi$ and $\mathrm{n}$ stand for TP cross-section, spectral integral area, quantum yield and concentration; s and $\mathrm{r}$ stand for sample and reference. Fluorescein (aqueous, $1 \mu \mathrm{M}, \mathrm{pH}=11$ ) was used as a reference probe. From $710 \mathrm{~nm}$ to $900 \mathrm{~nm}$, DCPO was calculated to have a two-photon absorption cross-section of $\delta_{\max }=30 \mathrm{GM}$ at $830 \mathrm{~nm}$ (Fig. 4a). The results demonstrate that BI-E could be used for $\mathrm{N}_{2} \mathrm{H}_{4}$ imaging by two-photon microscopy in cells.

(a)

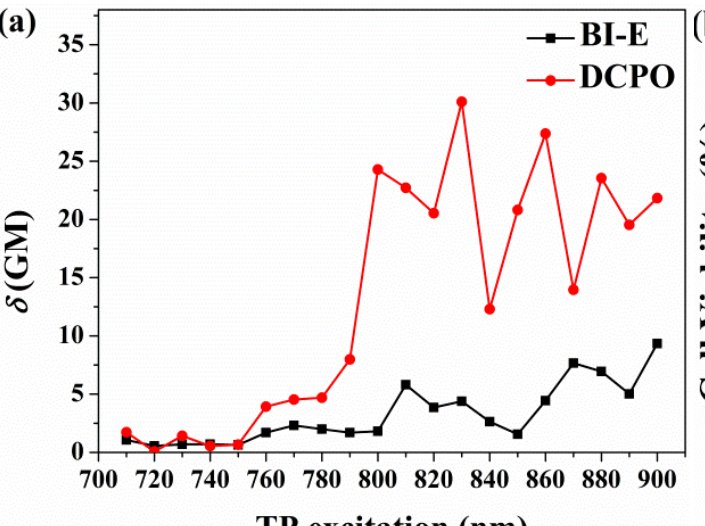

TP excitation (nm)

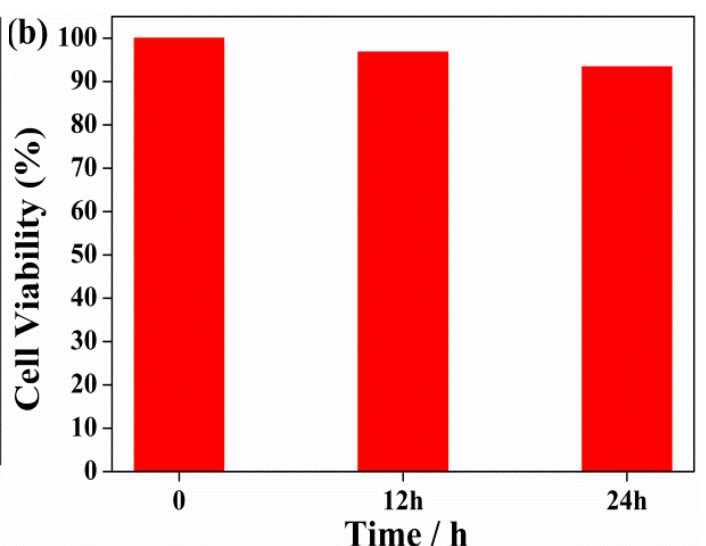

Time / h

Fig. 4. (a) Two-photon cross-section of BI-E and DCPO $(10 \mu \mathrm{M})$ in solution (Ethanol/PBS $=5 / 5, \mathrm{pH}=7.4)$. (b)

Cytotoxicity of BI-E probe. Cell viability of MCF-7 cells incubated with BI-E $(5 \mu \mathrm{M})$ for $12 \mathrm{~h}$ and $24 \mathrm{~h}$.

\subsection{Fluorescence bio-imaging and cytotoxicity assay}



incubated with $100 \mu \mathrm{M} \mathrm{N}_{2} \mathrm{H}_{4}$ for $15 \mathrm{~min}$, and then washed with DMEM three times. Subsequently, the cells were treated with $5 \mu \mathrm{M}$ BI-E for 30 min at $37^{\circ} \mathrm{C}$ and washed with DMEM three times.

Then remarkable red fluorescence was obtained in the cells by one-photon microscopy (OPM) imaging upon excitation at $559 \mathrm{~nm}$. But in the control test, little fluorescence was observed when the cells were treated with $5 \mu \mathrm{M}$ BI-E for $30 \mathrm{~min}$ at $37^{\circ} \mathrm{C}$. These results showed that BI-E has a selective response to $\mathrm{N}_{2} \mathrm{H}_{4}$ in living cells. Then imaging $\mathrm{N}_{2} \mathrm{H}_{4}$ in MCF-7 cells was examined by two-photon microscopy (TPM) imaging. Obvious red fluorescence observed in MCF-7 cells indicated that BI-E is a TP fluorescent probe with NIR emission for $\mathrm{N}_{2} \mathrm{H}_{4}$ in living cells (Fig. 5). $820 \mathrm{~nm}$ was chosen for TPM because of the difference between intracellular and extracellular environment. Moreover, the cytotoxicity of BI-E was investigated using a cell viability assay. MCF-7 cells were treated with $5 \mu \mathrm{M}$ BI-E for $12 \mathrm{~h}$ and $24 \mathrm{~h}$, and then cell viability was evaluated using a MTT assay. The results showed that cell viability was over $90 \%$ indicating that BI-E had low cytotoxicity (Fig. 4b).
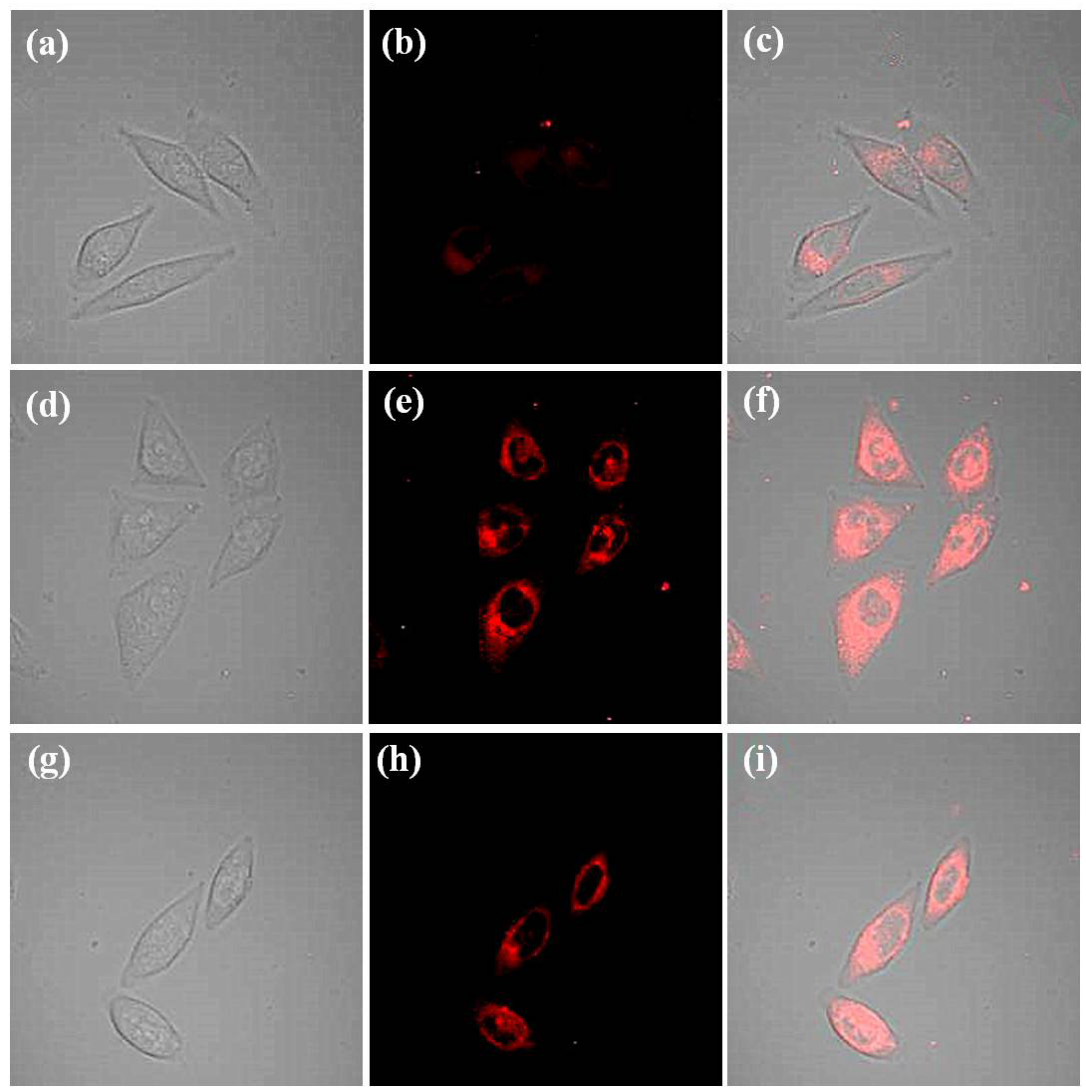

Fig. 5. Confocal microscope images of MCF-7 cells. (a), (b) and (c) cells treated with BI-E (5 $\mu \mathrm{M})$ for 30 min; 

was soaked in a DCM solution of BI-E (5 mM) and dried. Then, the filter paper was put into the solution of hydrazine at room temperature before observation. As shown, the color of filter paper changed gradually from yellow to deep pink with the increasing of the concentration of hydrazine in PBS buffer $(\mathrm{pH}=7.4)$ containing $50 \%$ of ethanol under $365 \mathrm{~nm}$ UV lamp (Fig. 6a). The color change of BI-E on the filter paper was dependent on the concentration of hydrazine in solution and was easy to distinguish by direct visualization. Besides, there was obviously fluorescence intensity increase after the filter paper exposed to $530 \mathrm{~nm}$ laser (Fig. 6b). The concentration of hydrazine at $0-10 \%$ results in obvious intensity increase on the paper. Compared to the probe described in literature[35], the emission of BI-E on the paper at $700 \mathrm{~nm}$ avoids low spectral application for detecting hydrazine in solution. 

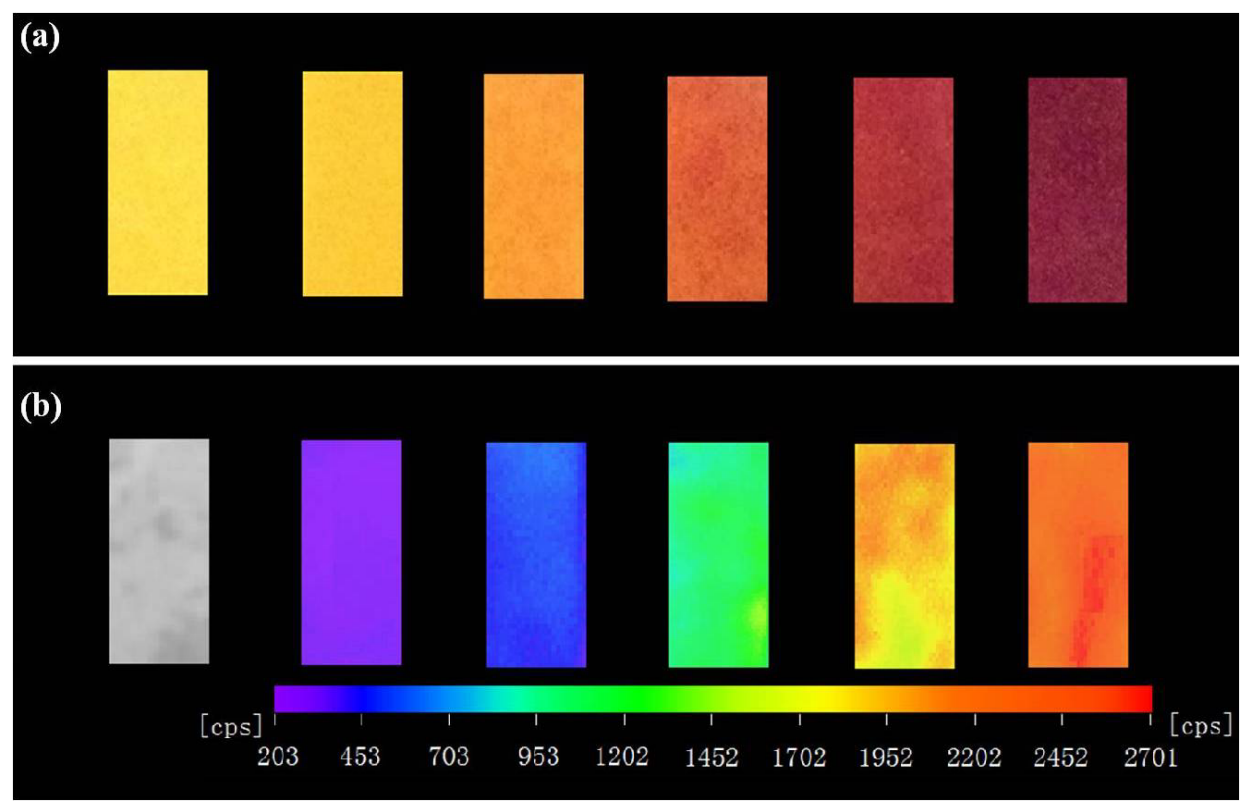

258 Fig. 6. The UV color (a) and FL intensity (b) changes of BI-E (5mM) coated filter paper after immersing into

259 different concentration of hydrazine solution for 5 second; the UV color changes were obtained using a hand-hold

260 UV lamp with an excitation at $365 \mathrm{~nm}$ (from left to right stand for $0,1 \%, 2.5 \%, 5 \%, 10 \%, 20 \%$ hydrazine solution

in Ethanol/PBS $=5 / 5, \mathrm{pH}=7.4)$, the FL intensity changes were obtained using a NightOWL II LB983 small

animal in vivo imaging system with an excitation laser of $530 \mathrm{~nm}$ and an emission filter of $700 \mathrm{~nm}$ (from left to

right stand for $0,0.05 \%, 0.1 \%, 1 \%, 5 \%, 10 \%$ hydrazine solution in Ethanol/ $\mathrm{PBS}=5 / 5, \mathrm{pH}=7.4$ ).

\section{Conclusions}

265 In summary, we have developed the two-photon probe BI-E, which selectively responds to

$266 \mathrm{~N}_{2} \mathrm{H}_{4}$ with an excellent NIR fluorescence turn-on effect, a good detection limit as low as $5.7 \times 10^{-8}$

$267 \mathrm{M}$ and a short response time $(1 \mathrm{~min})$. DCPO provides a two-photon cross-section $\delta_{\max }$ as high as

$26830 \mathrm{GM}$ at $830 \mathrm{~nm}$ in solution (Ethanol/PBS $=5 / 5, \mathrm{pH}=7.4$ ) and $\mathbf{B I}-\mathbf{E}$ has been successfully

269 applied to detect $\mathrm{N}_{2} \mathrm{H}_{4}$ in living cells by two-photon microscopy imaging. Moreover, the filter

270 paper coated with probe BI-E could be used to detect hydrazine in solution. Therefore, this work

271 provides a promising two-photon probing method for the rapid detection $\mathrm{N}_{2} \mathrm{H}_{4}$ in environmental 272 and biological samples.

273 Acknowledgments: This work was financially supported by the National Science Foundation of

274 China (21136002, 21421005). 
[1] Mo J-W, Ogorevc B, Zhang X, Pihlar B. Cobalt and copper hexacyanoferrate modified carbon fiber microelectrode as an all-Solid potentiometric microsensor for hydrazine. Electroanalysis. 2000;12:48-54.

[2] Cruz Vieira I, Omuro Lupetti K, Fatibello-Filho O. Sweet potato (Ipomoea batatas (L.) Lam.) tissue as a biocatalyst in a paraffin/graphite biosensor for hydrazine determination in boiler feed water. Anal Lett. 2002;35:2221-31.

[3] Serov A, Kwak C. Direct hydrazine fuel cells: A review. Appl Catal B: Environ. 2010;98:1-9.

[4] Ragnarsson U. Synthetic methodology for alkyl substituted hydrazines. Chem Soc Rev. 2001;30:205-13.

[5] Rothgery EF. Hydrazine and its derivatives. Kirk-Othmer Encyclopedia of Chemical Technology: John Wiley \& Sons, Inc.; 2000.

[6] Balsamo A, Macchia B, Macchia F, Rossello A, Giani R, Pifferi G, et al. Synthesis and antibacterial activities of new (.alpha.-hydrazinobenzyl)cephalosporins. J Med Chem. 1983;26:1648-50.

[7] Garrod S, Bollard ME, Nicholls AW, Connor SC, Connelly J, Nicholson JK, et al. Integrated metabonomic analysis of the multiorgan effects of hydrazine toxicity in the rat. Chem Res Toxicol. 2005; 18:115-22.

[8] Reilly CA, Aust SD. Peroxidase substrates stimulate the oxidation of hydralazine to metabolites which cause single-strand breaks in DNA. Chem Res Toxicol. 1997;10:328-34.

[9] Elder DP, Snodin D, Teasdale A. Control and analysis of hydrazine, hydrazides and hydrazones-genotoxic impurities in active pharmaceutical ingredients (APIs) and drug products. J Pharm Biomed Anal. 2011;54:900-10.

[10] Bhutani H, Singh S, Vir S, Bhutani KK, Kumar R, Chakraborti AK, et al. LC and LC-MS study of stress decomposition behaviour of isoniazid and establishment of validated stability-indicating assay method. J Pharm Biomed Anal. 2007;43:1213-20.

[11] Safavi A, Baezzat MR. Flow injection chemiluminescence determination of hydrazine. Anal Chim Acta. 1998;358:121-5.

[12] Collins GE, Rose-Pehrsson SL. Fluorescent detection of hydrazine, monomethylhydrazine, and 1,1-dimethylhydrazine by derivatization with aromatic dicarbaldehydes. Analyst. 1994;119:1907-13.

[13] Umar A, Rahman MM, Kim SH, Hahn Y-B. Zinc oxide nanonail based chemical sensor for hydrazine detection. Chem Commun. 2008:166-8.

[14] Malone HE. Determination of mixtures of hydrazine and 1,1-dimethylhydrazine. Anal Chem. 1961;33:575-7.

[15] Gu X, Camden JP. Surface-enhanced raman spectroscopy-based approach for ultrasensitive and selective detection of hydrazine. Anal Chem. 2015;87:6460-4.

[16] Zhang S, Fan J, Zhang S, Wang J, Wang X, Du J, et al. Lighting up fluoride ions in cellular mitochondria using a highly selective and sensitive fluorescent probe. Chem Commun. 2014;50:14021-4.

[17] Zhang H, Fan J, Wang J, Zhang S, Dou B, Peng X. An off-on COX-2-specific fluorescent probe: Targeting the golgi apparatus of cancer cells. J Am Chem Soc. 2013;135:11663-9.

[18] Yang Z, Lee JH, Jeon HM, Han JH, Park N, He Y, et al. Folate-based near-infrared fluorescent theranostic gemcitabine delivery. J Am Chem Soc. 2013;135:11657-62.

[19] Yu H, Zhang X, Xiao Y, Fang P, Lv C, Hou W. A mitochondrial-targetable and turn-on 
fluorescent probe based on nile red and monitoring for $\mathrm{H}_{2} \mathrm{~S}$ in living cells. Acta Chim Sinica. 2015;73:450-6.

[20] Fu Y, YF, Zheng T, Mu X, Sun F, Chen L. Reactive rhodamine fluorescent probes. Prog Chem. 2015;27(9):1213-29.

[21] Yu M, Wu X, Ding J, Wang L. Fluorescent film sensor based on starburst small molecular gelator with tetraphenyl arms for highly sensitive detection of TNT vapor. Chin J Appl Chem. 2015;32:604-10. [22] Chen X, Lee K-A, Ren X, Ryu J-C, Kim G, Ryu J-H, et al. Synthesis of a highly HOCl-selective fluorescent probe and its use for imaging $\mathrm{HOCl}$ in cells and organisms. Nat Protoc. 2016;11:1219-28.

[23] Gu K, Xu Y, Li H, Guo Z, Zhu S, Zhu S, et al. Real-time tracking and in vivo visualization of $\beta$-galactosidase activity in colorectal tumor with a ratiometric NIR fluorescent probe. J Am Chem Soc. 2016;138:5534-40.

[24] Xiong X, Zheng L, Yan J, Ye F, Qian Y, Song F. A turn-on and colorimetric metal-free long lifetime fluorescent probe and its application for time-resolved luminescent detection and bioimaging of cysteine. RSC Adv. 2015;5:53660-4.

[25] Gunnlaugsson T, Kruger PE, Jensen P, Tierney J, Ali HDP, Hussey GM. Colorimetric "naked eye" sensing of anions in aqueous solution. J Org Chem. 2005;70:10875-8.

[26] Chen X, Wang F, Hyun JY, Wei T, Qiang J, Ren X, et al. Recent progress in the development of fluorescent, luminescent and colorimetric probes for detection of reactive oxygen and nitrogen species. Chem Soc Rev. 2016;45:2976-3016.

[27] Hu C, Sun W, Cao J, Gao P, Wang J, Fan J, et al. A ratiometric near-infrared fluorescent probe for hydrazine and its in vivo applications. Org Lett. 2013;15:4022-5.

[28] Yu S, Wang S, Yu H, Feng Y, Zhang S, Zhu M, et al. A ratiometric two-photon fluorescent probe for hydrazine and its applications. Sens Actuators B Chem. 2015;220:1338-45.

[29] Li M, Wu X, Wang Y, Li Y, Zhu W, James TD. A near-infrared colorimetric fluorescent chemodosimeter for the detection of glutathione in living cells. Chem Commun. 2014;50:1751-3.

[30] Zhang X, Zhang L, Liu Y, Bao B, Zang Y, Li J, et al. A near-infrared fluorescent probe for rapid detection of hydrogen peroxide in living cells. Tetrahedron. 2015;71:4842-5.

[31] Wang P, Wang K, Chen D, Mao Y, Gu Y. A novel colorimetric and near-infrared fluorescent probe for hydrogen peroxide imaging in vitro and in vivo. RSC Adv. 2015;5:85957-63.

[32] Cao J, Zhao C, Zhu W. A near-infrared fluorescence chemodosimeter for fluoride via specific Si-O cleavage. Tetrahedron Lett. 2012;53:2107-10.

[33] Yu D, Zhang Q, Ding S, Feng G. A colorimetric and near-infrared fluorescent probe for biothiols and its application in living cells. RSC Adv. 2014;4:46561-7.

[34] Wang J, Li B, Zhao W, Zhang X, Luo X, Corkins ME, et al. Two-photon near infrared fluorescent turn-on probe toward cysteine and its imaging applications. ACS Sens. 2016;1:882-7.

[35] Goswami S, Das S, Aich K, Sarkar D, Mondal TK. A coumarin based chemodosimetric probe for ratiometric detection of hydrazine. Tetrahedron Lett. 2014;55:2695-9. 